\title{
Survey Nonresponse Trends and Fieldwork Effort in the 21st Century: Results of an International Study across Countries and Surveys
}

\author{
Annemieke Luiten ${ }^{1}$, Joop Hox ${ }^{2}$, and Edith de Leeuw ${ }^{2}$
}

\begin{abstract}
For more than three decades, declining response rates have been of concern to both survey methodologists and practitioners. Still, international comparative studies have been scarce. In one of the first international trend analyses for the period 1980-1997, De Leeuw and De Heer (2002) describe that response rates declined over the years and that countries differed in response rates and nonresponse trends. In this article, we continued where De Leeuw and De Heer (2002) stopped, and present trend data for the next period 1998-2015 from National Statistical Institutes. When we looked at trends over time in this new data set, we found that response rates are still declining over the years. Furthermore, nonresponse trends do differ over countries, but not over surveys. Some countries show a steeper decline in response than others, but all types of surveys show the same downward trend. The differences in (non)response trends over countries can be partly explained by differences in survey design between the countries. Finally, for some countries cost indicators were available, these showed that costs increased over the years and are negatively correlated with noncontact rates.
\end{abstract}

Key words: Response trend; noncontact; refusal; survey design; fieldwork; costs.

\section{Introduction}

Response rates are often seen as a major quality indicator for surveys by both data users and survey organizations (Stoop 2005). Statisticians point out that nonresponse threatens the sample selection mechanism of a survey where each member of the populations has a known and non-zero probability of being included, and as a consequence the validity of inference about the population may be at stake (Bethlehem et al. 2011; Brehm 1993; Groves and Couper 1998). Furthermore, nonresponse results in smaller realized sample

1 Statistics Netherlands, P.O. Box 4481, 6401 CZ Heerlen. the Netherlands. Email: a.luiten@cbs.nl

2 Department of Methodology and Statistics, Utrecht University, P.O. Box 80140, 3508 TC, Utrecht, the Netherlands. Emails: joophox@xs4all.nl and e.d.deleeuw@uu.nl

Acknowledgments: The authors thankfully acknowledge all researchers who so very generously gave their time to complete our nonresponse questionnaire - without their effort this study could not have been completed. We also thank Barry Schouten for his helpful comments on the data collection procedure and the participants of the International Workshop on Household Survey Nonresponse 2016, 2017 and 2018 for their extremely useful feedback on earlier versions. Thanks are also due to the reviewers and editors for their insightful comments. Finally, we thank and honour Wim de Heer, who designed and completed the first international nonresponse study. The views expressed are those of the authors and do not necessarily reflect the policies of Statistics Netherlands. 
sizes, and may result in longer fieldwork periods, and increased costs per completed interview.

Nonresponse occurs when a sample unit does not respond to a request to be surveyed. Two major components of unit nonresponse are non-contacts and refusals, and besides response rates, contact rates and refusal rates are important indicators for the evaluation of surveys and their fieldwork (AAPOR 2016). Therefore, it is not surprising that survey methodologists and statisticians have been concerned with the contactability and willingness of sample units (Groves and Couper 1998; Stoop 2005). This distinction was emphasized by Norman Bradburn, who in his 1992 presidential address to the American Association of Public Opinion Research declared "We all believe strongly that response rates are declining and have been declining for some time." Bradburn $(1992,392)$ then explicitly pointed out that "Part of the problem is locating respondents and part of the problem is getting respondents." A similar conviction was expressed by Groves (1989, 182) who stated that: "Participation in social surveys appears to be declining in the United States over time. This is true for government, academic, and commercial surveys."

One of the first trend studies in the United States was by Steeh (1981), who reported that between 1952 and 1979 refusals did increase in two major academic face-to-face interview studies (the US National Election Studies and the US Consumer Attitudes Survey); however Steeh did not study noncontacts. Curtin et al. (2005) investigated response trends for the US Survey of Consumer Attitudes covering the later period 1979 to 2003. During that period, data were collected using telephone interviews. Like Steeh (1981), Curtin et al. (2005) found that overall response rates for the Survey of Consumer Attitudes were decreasing over time; in addition, they showed that this decrease was partly caused by an increase in refusals and partly by an increase in noncontacts, especially after 1985.

A large comparative study for several governmental health and economic interview surveys in the United States was performed by Atrostic et al. (2001), who investigated nonresponse trends for six major US household surveys: the Current Population Survey (CPS), the Consumer Expenditure Survey (CE), the Diary and Quarterly Surveys (CED and CEQ), the National Health Interview Survey (NHIS), the National Crime Victimization Survey (NCVS) and the Survey of Income and Program Participation (SIPP). Although these surveys differ in design and fieldwork, they also have design and data collection features in common, and the first interview is always conducted by a personal visit after an introductory letter is sent to the household's address. Atrostic et al. (2001) concluded that overall nonresponse increased for all six surveys over the period 1990 to 1999 with a clear increase in 1994. Again, this increase in nonresponse was caused by an increase in both refusals and noncontacts, with the noncontact rates showing the greatest relative increase.

Building on these earlier studies, Williams and Brick (2018) updated nonresponse trends for nine face-to-face household surveys conducted in the United States since 2000. These surveys covered a variety of topics, mostly on health related issues but also on economics, crimes and social attitudes and include the CPS, NHIS and NCVS mentioned by Atrostic et al. (2001), but also the General Social Survey (GSS) and the National Survey on Drug Use and Health (NSDUH), the Medical Expenditure Panel Survey (MEPS), the Medicare Current Beneficial Survey (MCBS), the National Health and Nutrition Examination Survey (NHANES) and the National Survey of Family Growth 
(NSFG). Most surveys had high response rates in the 1990s, but response was slowly decreasing over time. Williams and Brick (2018) concluded that in the United States, the overall response rates for nine major face-to-face surveys clearly decreased in the period $2000-2014$, and are at present at $70 \%$ to $80 \%$. This decrease in response is attributed to a clear increase in both the noncontacts and the refusals; with refusals as the main reason for nonresponse.

The still relatively high response rates of $70-80 \%$ for face-to-face surveys in the United States are in sharp contrast to those for telephone interviews. Curtin et al. (2005) for the Survey of Consumer Attitudes reported a decline from $72 \%$ in 1979 to $48 \%$ in 2003, and ten years later in 2013 the response had dropped to 16\% (Dutwin and Lavrakas 2017). Furthermore, Pew Research (2012) reported a decrease in response rates from 36\% in 1997 to $9 \%$ in 2012. Again, both contactability and willingness to cooperate declined. From 1997 to 2012 , contact rates dropped from $90 \%$ to $62 \%$ and cooperation rates more than halved from $43 \%$ to $14 \%$. This is corroborated by results for the Gallup Poll Social Survey Series (Marken 2018), which showed a drop in response rates from 28\% in 1997 through $9 \%$ in 2012 to $7 \%$ in 2017.

Traditionally, studies on nonresponse trends were mainly done in the United States; European and international trend data on nonresponse are much scarcer. An early study by Hox and De Leeuw (1994) summarized data from 45 mode comparison studies in Europe, the United States and Canada for the period 1947-1992. Using meta-analytic techniques, they concluded that although face-to face surveys still obtained the highest overall response rates, there was a downward trend over the years. A similar downward trend in response was found for telephone surveys, but not for postal mail surveys. The relative stable trend for mail surveys was attributed to the increased research effort and attention for improving mail surveys in that period (e.g., Dillman 1978), counteracting a potential downward trend.

To accommodate the need for comparable international response data, an initiative was started at the first International Workshop on Household Survey Nonresponse to collect longitudinal data. An international nonresponse questionnaire was developed that was sent yearly to contacts at governmental survey agencies in different countries. The goal was to collect long-term, cross-national comparable data from governmental survey agencies on surveys that were regularly conducted. The questionnaire contained questions on response, noncontact and refusal rates, as well as questions on sampling and survey design, fieldwork and survey organization. This resulted in a final data set covering the period 1980-1997 and time series were available for 16 countries and 10 different interview surveys (De Heer 1999; De Leeuw and De Heer 2002). The main data collection mode used was the face-toface interview, although some National Statistical Institutes (Finland, Sweden) used telephone interviews. A multilevel analysis by De Leeuw and De Heer (2002) showed that response rates had indeed been declining. Both noncontact rates and refusal rates increased over the period 1980-1997, with an average of $0.2 \%$ per year for noncontact rates and $0.3 \%$ per year for refusal rates. Furthermore, countries and surveys differed in the acceleration of refusal rates, while noncontact rates decreased to the same extent across countries.

Recently, Beullens et al. (2018) analyzed seven rounds of the European Social Survey (ESS). Response data for the ESS, which is a face-to-face survey, from 36 European countries were available. As the ESS is fielded every two years, the data set covered a time 
period of 12 years (2002-2014). Beullens et al. (2018) report a tendency for response rates to decrease over time. They also conclude that their findings support the results reported by De Leeuw and De Heer (2002) for international official statistics. Furthermore, Beullens et al. (2018) point out that contrary to other nonresponse trend studies, the noncontact rates appear to be more or less stable in the European Social Survey, probably due to the increased fieldwork efforts over the years in many countries for the ESS. Therefore, they attribute the declining response rates in the ESS to the increase in refusal rates and conclude that obtaining cooperation has become increasingly difficult over time.

In 2015, an initiative was taken at the yearly International Nonresponse Workshop to collect new international response data following up the analyses by De Leeuw and De Heer (2002), who described the period 1980-1997. The new data set covered the period 1998-2015. For the Labour Force Survey (LFS) the response trend data (1980-1997) from De Leeuw and De Heer (2002) were still available. De Leeuw et al. (2018) combined the new LFS response trend data (1998-2015) with the old LFS response trend data (1980-1997). They concluded that for the Labour Force Survey, the trends visible in De Leeuw and De Heer (2002) continue almost unchanged over time with possibly a small deceleration in refusal rates. The response for the LFS decreased by an average of $0.73 \%$ each year. Both the noncontacts and the refusals increased over the total time period, but countries differed in refusal and noncontact rates. De Leeuw et al. (2018) also detected that the difference in year trends for refusals between the old (1980-1997) data and the recent (1998-2015) data was significant. This indicates that although refusals for the LFS are still increasing in the new millennium, the rate of increase is slightly smaller. This study could not investigate the differences in trends any further due to a lack of descriptive variables, as the full 1980-1997 data set and the completed questionnaires unfortunately were no longer archived. The still available 1980-1997 data set contained, besides response trend data, only the information whether the survey was mandatory or not. As could be expected, mandatory surveys did result in fewer refusals than voluntary surveys and hence in a higher response, but the response trends in mandatory and voluntary surveys were comparable (De Leeuw et al. 2018).

In sum: In the US response rates have been declining over the years for a variety of surveys. This trend was stronger for telephone than for face-to-face interviews. The growing nonresponse was partly caused by an increase in noncontacts and partly by an increase in refusals. In addition, for international surveys a clear decline in response could be found and an increase in refusals could be clearly discerned. However, Beullens et al. (2018) did not find an increase in noncontacts for the European Social Survey. On the other hand, De Leeuw et al. (2018) do detect an increase in both noncontacts and nonresponse for a very long international time series concerning the Labour Force Survey.

Neither Beullens et al. (2018) nor De Leeuw et al. (2018) could directly link fieldwork and context variables to nonresponse data in order to explore the nonresponse trends and differences found. Furthermore, the type of survey (ESS vs LFS) could play a role too, as the LFS and ESS clearly differ in topic and type of questions asked, which raises the questions of the generalizability of the findings. In order to investigate this further, we analyzed the new nonresponse data set collected in 2015 (Luiten et al. 2016). This new data covers the period 1998-2015 only, but does contain data for a variety of surveys and 
information on meta-variables describing fieldwork and design. This enables us to address the following research questions:

1. In the first two decades of the new millennium, can decreasing response trends in noncontacts and refusals be observed for international surveys, as in the United States?

2. Are these trends generalizable over different surveys or do surveys differ in nonresponse trends?

3. Are these trends different for different countries?

4. Which factors in survey design and fieldwork effort are related to nonresponse trends?

\section{Methods}

\subsection{Data Collection}

In 2015, a new version of the International Questionnaire on Nonresponse was developed (Luiten et al. 2016). This new questionnaire was based on the original questionnaire as developed and used by De Heer (1999, see also De Leeuw and De Heer 2002), with added questions on mixed-mode-designs, fieldwork efforts, and costs. These variables were included based on their potential influence on noncontacts and refusals as reported in the literature on nonresponse (Biemer and Lyberg 2003; Dillman et al. 2002; Dillman et al. 2014; Groves and Couper 1998; Groves et al. 2004; Stoop 2005, 2016). Two versions of the questionnaire were available, one for the Labour Force Survey (LFS) and one for another important social survey of choice. The two versions overlap in questions asked, but for replicability and transparency both questionnaires are fully available as online supplemental material, Section 1.

The data were collected in 2016 and the two questionnaires were sent out to National Statistical Institutes (NSI) in Europe, Australia, Canada, and the United States. Respondents were asked to report on response, refusal and contact rates for the period 1998 to 2015 for the LFS and for one other important social survey at their institute. In addition, they were asked to give details on design, fieldwork efforts and costs, and on any changes made from 1998 to 2015.

In total, 25 countries participated, both European and non-European countries: Austria, Australia, Belgium, Bulgaria, Canada, Croatia, Iceland, Finland, France, Germany, Hungary, Italy, Latvia, Lithuania, Malta, the Netherlands, Norway, Poland, Portugal, Slovakia, Slovenia, Sweden, Switzerland, the United Kingdom, and the United States. All countries provided information on the LFS.

Several countries also provided information for one or more social surveys. Nine countries completed the full questionnaire with longitudinal response data (1998-2015) for the Household Budget Survey (HBS), and three countries returned a completed questionnaire and reported response time series (1998-2015) for the Survey of Income and Living Conditions (SILC). Furthermore, one county provided data for the European Social Survey (ESS), one for the National Travel Survey (NTS), one for the Consumer Barometer (CB), and one for the Survey on Social Cultural Changes (SCC). A detailed description of these seven surveys, number of institutes, and a summary of design and fieldwork procedures can be found in the online supplemental material, Section 2. 
Countries not only differ in survey design and fieldwork procedures but also in demographics and economic conditions. These macro-level factors, which are not under the control of the researcher, may influence response (Groves and Couper 1998; De Leeuw and De Heer 2002; Bethlehem et al. 2011). Therefore, in addition to the available questionnaire data, we collected economic and demographic data for all participating countries over the relevant time period 1998-2015. Available data from the Worldbank, the Organization for Economic Cooperation and Development (OECD), and Eurostat, included (1) 'employment rate, persons 15-64', (2) 'GDP per capita' (gross domestic product by population), which is an indicator of a country's standard of living, (3) the GINI-coefficient, which measures inequality in income and wealth, (4) the life expectancy at birth, and (5) the percentage of single households in a country.

\subsection{Data Cleaning and Index Construction}

In a preliminary analysis, the data were screened for missingness and variance. Variables that contained a large fraction of missing values (such as interviewer workload) were omitted. In addition, variables that showed (almost) no variance across countries and years (such as the use of an advance letter) were omitted. See also the online supplemental material, Section 2.

\subsubsection{Index Construction}

There are five economic and demographic macro-level variables available for the analysis of 25 countries. In general, multivariate analyses require about ten cases per variable (Tabachnick and Fidell 2013), so we can use only two to three variables. To summarize the macro-level information, we carried out a latent class analysis (Muthén and Muthén 2017, 8.2.) with the five macro-level variables as class indicators and two levels: years within countries. At the within-country level, one year was added as a control variable, and a full covariance matrix was estimated. A two-class model had the best fit and had a straightforward interpretation: the two classes clearly distinguished between countries with low and high economic development. Countries in Class 1 were Bulgaria, Croatia, Hungary, Latvia, Lithuania, Malta, Poland, Portugal, Slovakia, and Slovenia. Countries in Class 2 were Australia, Austria, Belgium, Canada, Finland, France, Germany, Iceland, Italy, the Netherlands, Norway, Sweden, Switzerland, the United Kingdom, and the United States. A class membership variable was added as contextual variable to the data.

\subsection{Data Analysis}

The literature on nonresponse (Bethlehem et al. 2011; Biemer and Lyberg 2003; Dillman et al. 2002; De Heer 1999; De Leeuw and De Heer 2002; Groves and Couper 1998; Groves et al. 2004; Stoop 2005; Stoop et al. 2010) distinguishes three theoretical groups of variables that influence nonresponse. (1) Context or macro level variables that describe the social and economic environment and are not under the influence of the researcher; an example is the economic conditions of a country. (2) General design variables that are mostly under the control of the researcher or agency, such as sampling procedures. (3) Fieldwork organization/effort related variables that are under the control of the researcher, but may be restricted by available budget, such as use of incentives. 
After screening on missingness and variance, the available predictor variables were assigned to the three groups. The assignment was based on the literature cited. The latent class indicator economic development was used as a 'country context' variable. Available 'general design' variables that may influence the response are, for instance, mandatory versus voluntary survey, mixed-mode used, type of sample, oversampling, substitution allowed, proxies allowed. Examples of available 'effort in field work' variables are interviewer rewards, refusal conversion, reassignment of interviewers, respondent incentives. All variables were recorded in such a way that a high score indicates a high frequency or amount of the referred attribute. For a complete list of explanatory variables and their classification in the three groups, see Appendix, Section 5.

A cross-classified multilevel analysis (Hox, et al. 2018) was carried out with years nested within the cross-classification of countries and surveys. Dependent variables were response rate $(\mathrm{N}=535)$, noncontact rate $(\mathrm{N}=485)$, and refusal rate $(\mathrm{N}=485)$. These rates were expressed as proportions and because the distributions were rather skewed, a logit transformation was performed to increase normality of the distributions. To model the trend over time, year of data collection was included. For ease of interpretation, this was coded as $1998=0,1999=1$ and so on. As a control variable, we added a variable that indicated whether ineligibles were excluded or not in the response rate as reported by the agencies (RRcorrected).

\section{Results: International Response Trends 1998-2015}

\subsection{International Trends: Preliminary Analyses}

We have data on the LFS and a variety of other social surveys. To analyze whether the LFS and the other social surveys show the same response trends, we performed separate multilevel analyses on response, noncontact, and refusal as dependent variable and with year as explanatory variable, for the LFS and the other surveys. This enabled us to formally test the equality of the regression coefficients of the LFS versus the social surveys (Guilford and Fruchter 1978, 148).

The analyses showed that only the intercepts differed between surveys, but not the trends over time. The differences in intercepts indicated a higher overall response and fewer refusals for the Labour Force Survey than for the other social surveys $(p<.01)$, but no differences in noncontacts. However, the trends over time for overall response, noncontact, and refusal rates did not differ between the different types of surveys. The results indicate that we may combine the different surveys into one analysis, provided we accommodate the differences in intercepts for refusal and response. Therefore, the substantive analyses are specified as cross-classified nested data structures with years nested within a cross-classification of surveys and countries (Hox et al. 2018). In addition, we include the slope variance for years in countries and surveys. For details of the preliminary analyses, see online supplemental material, Section 3.

\subsection{International Trends: Response Rates, Noncontacts, and Refusals}

We investigate whether international surveys, like US-based surveys, show decreasing response rates in the first two decades of the new millennium. In our analysis of 
international trend data for the period 1998-2015, we focus on three dependent variables. Besides general response rate, we distinguish between the two main components of nonresponse: noncontacts and refusals. Both noncontacts and refusals contribute to the overall nonresponse, but different factors influence each source (Bradburn 1992; Groves and Couper 1998; Stoop 2005). Furthermore, contact rates and refusal rates are important indicators for the evaluation of surveys and their fieldwork (AAPOR 2016).

In addition, we investigate if these trends generalize over different surveys and if these trends are different for different countries. Finally, we explore which factors in survey design and fieldwork effort are related to nonresponse trends.

Analyses were performed separately for the logit of proportion overall response, noncontacts, and refusals. We start with the 'null'-model, a model without any explanatory variables. The results for the null model are summarized in Table 1.

The significant variances over countries and over surveys estimated in this null-model show that the absolute (non)response rates differ between countries and between surveys. Furthermore, the first column shows that the variance for countries $(0.56)$ is larger than for surveys (0.15). This means that the differences in absolute response rates between the countries are far larger than the differences in response rates between different surveys. The same conclusions hold for noncontact rate (Column 2) and refusal rate (Column 3): there are larger differences between countries concerning noncontact and refusal rates than between surveys.

The response does differ between countries and between surveys, but is there a general downward trend in survey response internationally over the years 1998-2015 (Research Question 1). To answer this research question, we added the explanatory variable 'year' to the (null) model. Again, the dependent variables were response, noncontact, and refusal, and all surveys (LFS and social surveys) were analyzed together. First, we tested if year had a significant variance component at the country or survey level. The analysis showed that there is no significant variance for year between surveys (smallest $p>.08$ ), but there is a significant variance between countries (largest $p<.01$ for all three tests). This is an important result, indicating that, although surveys do differ in absolute response, the trend over time is the same for all surveys. Thus, although the topic of the survey may influence the achieved response rate (Dillman et al. 2002; Groves and Couper 1998; Stoop 2005), it does not influence response trends. Furthermore, the significant variances for year between

Table 1. Nonresponse: 1998-2015.

Null-model for response, noncontact, and refusal logits over surveys and countries

\begin{tabular}{lccc}
\hline Fixed part & Response logit & Noncontact logit & Refusals logit \\
\hline Intercept & $1.07(.21)$ & $-2.60(.22)$ & $-1.91(.31)$ \\
Random part (Variances) & & & \\
Over surveys & $0.15(.09)$ & $0.17(.12)$ & $0.52(.32)$ \\
Over countries & $0.56(.17)$ & $0.41(.13)$ & $0.68(.21)$ \\
Residual & $0.13(.01)$ & $0.22(.01)$ & $0.28(.02)$ \\
\hline N Countries/surveys & $25 / 7$ & $23 / 7$ & $23 / 7$ \\
\hline
\end{tabular}

Note: Dependent variables are response rate, noncontact rate and refusal rate. Parameter estimates are on a logit scale and are not proportions. Standard errors in parentheses. All estimates are significant at $p<0.05$. 
countries indicate that the trends over time do indeed differ over countries. To investigate this further, a cross-classified multilevel model was specified with slope variation for year at the country level only. The results are summarized in Table 2.

The first column of Table 2 shows that the parameter estimate for 'year' is significant. This means that there is a negative trend in response from year to year for international surveys. The response rate indeed decreases over the period 1998-2015 (Research Question 1). The regression coefficient of -0.03 for the logit of the response in Table 2 translates into a decrease in response rate by approximately 0.59 percentage point for each year. The decrease in response rates over the years is caused by significant increases in both noncontacts (regression coefficient 0.03) and refusals (regression coefficient $0.03)$.

With the predictor variable 'year' added to the model, the variance over surveys is no longer significant compared to the null model, but the variance over countries still remains significant. An important finding is that the variance of the regression coefficients for year over countries is small but significant. The variance for year over countries for the response rate in Column 1 of Table 2 is 0.001 , which indicates small but significant differences in the response trends between countries. The variation in response trends is related to significant variation for year over countries in the trends for both noncontacts and refusals, as shown in Column 2 and 3 of Table 2. In sum: the downward trend for response rates does not differ between different surveys (Research Question 2), but the trends are different between different countries (Research Question 3). Similarly, the increasing trends for noncontact and refusal rate do not differ between surveys, but they do differ between countries.

\subsection{International Response Trends: Country Context, Survey Design and Fieldwork Efforts}

An important finding was that for international surveys there is a downward trend in response and that there is a significant cross-country variation in the response trends.

Table 2. Response trends in the period 1998-2015.

Effects of year on response, noncontact and refusal logits over surveys and countries

\begin{tabular}{lccc}
\hline Fixed part & Response logit & Noncontact logit & Refusal logit \\
\hline Intercept & $1.38(.23)$ & $-2.97(.25)$ & $-2.21(.34)$ \\
Year & $-0.03(.01)$ & $0.03(.01)$ & $0.03(.01)$ \\
Random part (Variances) & & & \\
Over surveys & $0.18(.11)^{n s}$ & $0.23(.15)^{n s}$ & $0.63(.38)^{n s}$ \\
Over countries & $0.59(.18)$ & $0.55(.19)$ & $0.40(.16)$ \\
Year over countries & $0.001(.0004)$ & $0.001(.0005)$ & $0.002(.0007)$ \\
Residual & $0.08(.01)$ & $0.16(.01)$ & $0.22(.01)$ \\
\hline N countries/surveys & $25 / 7$ & $23 / 7$ & $23 / 7$ \\
\hline
\end{tabular}

Note: Dependent variables are response rate, noncontact rate and refusal rate. Parameter estimates are on a logit scale and are not proportions. Year is coded $1998=0$. Standard errors in parentheses. All estimates are significant at $p<0.05$, unless indicated by $n s$. 
Countries do differ in response, noncontact, and refusal trends, which give rise to the question which factors in survey design and fieldwork effort are related to these nonresponse trends (Research Question 4). Three groups of variables were available as explanatory variables to include in the trend models:

1. Context Variable. On the country level, a latent class indicator describing economic development was created (see Subsection 2.2.1.). Although not under the control of a research institute or researcher, the economic conditions of a country may influence response propensity (De Leeuw and De Heer 2002; Groves and Couper 1998; Harris-Kojetin and Tucker 1999; Larsen et al. 2020, this issue).

2. General Survey Design Variables. Whether or not a survey is mandatory may reduce refusals and enhance general response (De Leeuw and De Heer 2002). Type of sample may influence response in several ways; a household/address sample is expected to have lower noncontact rates than a person sample, but it may have lower general response rates (Stoop et al. 2010, chap.2). Likewise, under- and oversampling of certain groups may influence response. Rules for allowing proxy respondents and for substitution of noncontacts and refusals differ for different surveys. In general, it is expected that a more lenient approach in design and allowing for proxies and for substitution enhances response (Stoop 2016; Vehovar 1999). Multiple, or mixed-mode, studies are at present used as a means to improve response at affordable costs, but the empirical evidence of their effect on response is still scarce (De Leeuw 2018). Representativity, or R-indicators, have been introduced as a quality indicator of response and are used at Statistical Institutes to compare the response to different surveys (Bethlehem et al. 2011). Although, these representativity indices do not directly influence response, they may support better monitoring and targeting nonresponse (Schouten et al. 2011). Finally, allowing for interventions in fieldwork and adapting to the situation may improve response (Chun et al. 2018; Tourangeau et al. 2016).

3. Effort in Fieldwork Variables. The position and working conditions of interviewers may play an important role in attained response. De Heer (1999) already pointed out that employment condition of interviewers plays a role; furthermore, motivating interviewers through a reward or sanction unwanted interviewer behaviour also may influence (non)response (Groves and Couper 1998). Refusal conversion and the use of special 'refusal' letters to motivate initial nonrespondents appear to have a beneficent effect on response; for an overview see AAPOR (2014). The limited number of studies on reassignment of initial nonrespondents to new interviewers shows conflicting evidence. For an overview, see Peeters et al. 2020, this issue. Finally, meta-analyses and overviews show that the use of respondent incentives has a positive effect on response (e.g., Singer 2002; Singer and Ye 2013). Adding these variables as predictors to the model leads to the results summarized in Table 3. As some agencies omitted ineligibles in their response rate calculation, we also included a control variable (RRcorrected) indicating whether the RR reported in the questionnaire included this correction.

Although 19 time-varying variables describing country context, survey design, and fieldwork effort were added to the model, and several of these variables are 
Table 3. Predicting response, noncontact and refusal logits over surveys and countries: 1998-2015.

\begin{tabular}{|c|c|c|c|}
\hline Fixed part & $\begin{array}{l}\text { Response } \\
\text { logit }\end{array}$ & $\begin{array}{l}\text { Noncontact } \\
\text { logit }\end{array}$ & $\begin{array}{c}\text { Refusal } \\
\text { logit }\end{array}$ \\
\hline Intercept & $0.60(.66)^{\mathrm{ns}}$ & $-2.88(.78)$ & $-0.26(.99)^{\mathrm{ns}}$ \\
\hline Year & $-0.03(.01)$ & $0.03(.01)$ & $0.03(.01)$ \\
\hline \multicolumn{4}{|l|}{ Country context variable } \\
\hline $\begin{array}{l}\text { Economic development } \\
\text { (high) }\end{array}$ & $-0.26(.38)^{\mathrm{ns}}$ & $0.68(.47)^{\mathrm{ns}}$ & $-0.20(.50)^{\mathrm{ns}}$ \\
\hline \multicolumn{4}{|l|}{ General design variables } \\
\hline Mandatory & $0.80(.31)$ & $-1.27(.27)$ & $-1.11(.36)$ \\
\hline $\begin{array}{l}\text { HH/address sample (1 versus } \\
\text { person sample } 0)\end{array}$ & $0.90(.32)$ & $0.05(.28)^{\mathrm{ns}}$ & $-2.05(.33)$ \\
\hline Undersampling & $-0.59(.38)^{\mathrm{ns}}$ & $-0.25(.37)^{\mathrm{ns}}$ & $0.65(.46)^{\mathrm{ns}}$ \\
\hline Oversampling & $0.42(.13)$ & $-0.13(.19)^{\mathrm{ns}}$ & $-0.52(.16)$ \\
\hline Proxy allowed & $-0.32(.25)^{\mathrm{ns}}$ & $0.54(.35)^{\mathrm{ns}}$ & $0.82(.38)$ \\
\hline Subst. noncont & $-1.44(.31)$ & $0.18(.40)^{\mathrm{ns}}$ & $2.23(.42)$ \\
\hline Subst. refusal & $1.77(.34)$ & $-0.17(.44)^{\mathrm{ns}}$ & $-2.47(.45)$ \\
\hline Mixed-mode & $-0.11(.05)$ & $0.17(.08)^{\mathrm{ns}}$ & $0.10(.07)^{\mathrm{ns}}$ \\
\hline $\mathrm{R}$ indicators used & $-0.74(.33)$ & $1.60(.42)$ & $-0.54(.36)^{\mathrm{ns}}$ \\
\hline Interventions allowed & $0.88(.25)$ & $0.19(.26)^{\mathrm{ns}}$ & $-1.07(.26)$ \\
\hline \multicolumn{4}{|l|}{ Effort in fieldwork variables } \\
\hline $\begin{array}{l}\text { Own interviewers ( } 1 \text { versus } \\
\text { External } 0 \text { ) }\end{array}$ & $0.24(.24)^{\mathrm{ns}}$ & $-0.11(.35)^{\mathrm{ns}}$ & $-0.30(.45)^{\mathrm{ns}}$ \\
\hline Reward interviewers & $-0.05(.33)^{\mathrm{ns}}$ & $-0.39(.38)^{\mathrm{ns}}$ & $0.23(.43)^{\mathrm{ns}}$ \\
\hline Sanction interviewers & $-0.39(.30)^{\mathrm{ns}}$ & $0.02(.36)^{\mathrm{ns}}$ & $0.97(.42)$ \\
\hline Refusal conversion & $-0.10(.13)^{\mathrm{ns}}$ & $-0.01(.19)^{\mathrm{ns}}$ & $-0.06(.16)^{\mathrm{ns}}$ \\
\hline Reassignment & $-0.09(.16)^{\mathrm{ns}}$ & $-0.92(.21)$ & $0.13(.20)^{\mathrm{ns}}$ \\
\hline Special refusal letters & $0.38(.30)^{\mathrm{ns}}$ & $0.31(.41)^{\mathrm{ns}}$ & $-0.38(.44)^{\mathrm{ns}}$ \\
\hline Incentives & $-0.01(.22)^{\mathrm{ns}}$ & $-0.60(.32)^{\mathrm{ns}}$ & $0.85(.36)$ \\
\hline \multicolumn{4}{|l|}{ Control variable } \\
\hline RRcorrected for ineligibles & $-0.13(.21)^{\mathrm{ns}}$ & Not applicable & Not applicable \\
\hline Random part & Variance & Variance & Variance \\
\hline Over surveys & $0.48(.33)^{\mathrm{ns}}$ & $0.12(.12)^{\mathrm{ns}}$ & $0.64(.48)^{\mathrm{ns}}$ \\
\hline Over countries & $1.02 \quad(.35)$ & $1.23 \quad(.49)$ & $1.70 \quad(.64)$ \\
\hline Year over countries & $0.001(.000)$ & $0.001(.000)$ & $0.001(.001)$ \\
\hline Residual & $0.05 \quad(.00)$ & $0.11 \quad(.01)$ & $0.07 \quad(.00)$ \\
\hline $\mathrm{N}$ countries/surveys/records & $25 / 7 / 470$ & $23 / 7 / 432$ & $23 / 7 / 434$ \\
\hline
\end{tabular}

Note: Dependent variables are response rate, noncontact rate and refusal rate. Parameter estimates are on a logit scale and are not proportions. Year is coded $1998=0$. All variables are coded $0=$ no, not applicable, $1=$ yes, applicable. Standard errors in parentheses. All estimates are significant at $p<0.05$, unless indicated by ns.

significantly related to nonresponse, the nonresponse trends over years retain their significance.

Which factors are related to the nonresponse trend? (Research Question 4). The patterns of significant time-varying predictors of response, noncontacts and refusals clearly show that mainly the general design variables are related to the nonresponse trends. Disappointingly, the fieldwork effort variables are hardly related to nonresponse, and the socio-economic development of the countries is not related to any of the nonresponse trends. 
The significant predictors of response rate are mostly related to refusals. With the available variables, the overall response rate is associated with the design variables 'mandatory', 'type of sample (person vs household/address)', 'oversampling', 'substitutions allowed', 'use of more than one mode (mixed-mode)', 'representativity (R)-indicators used', and 'interventions in fieldwork allowed'. No effort variables were significantly associated with response rate.

Refusal rate can be predicted better than noncontact rate. Refusal rate is again associated with the design variables 'mandatory', 'type of sample', 'oversampling', 'substitutions allowed', and 'intervening in fieldwork'. The design variable 'proxies allowed', and the effort variable 'incentive for respondents' are also associated with refusal rate, but not with overall response rate.

Finally, noncontact rate is associated with the design variables 'mandatory', 'Rindicators used', and the fieldwork effort variable 'reassignment of cases to special interviewers'.

It is not surprising that mandatory surveys result in higher response rates, due to both lower noncontacts and lower refusals; however, this variable is not under the control of an individual researcher. When households are sampled, this results in a higher response rate than when persons are sampled, due to lower refusals. Similarly, oversampling leads to a higher response, again due to lower refusals. Interestingly, allowing substitution for noncontacts does not influence noncontact rate, but is associated with an increase in refusals and, as a result, a decrease in response rate. Allowing substitutions for refusals and allowing interventions in the field leads to increased response rates and decreased refusal rates.

It should be noted that the results reported above in Table 3 are descriptive, and that correlation alone does not imply causality. This is illustrated by two counterintuitive results. When an agency uses a mixed-mode design or R-indicators, this is associated with a lower response rate. This does not mean that the use of R-indicators causes lower response rates. It is far more likely that when agencies encounter decreasing response rates, they want to know if it affects the representativity and check this with R-indicators. Similarly, adopting a mixed-mode design may be a reaction to growing nonresponse. We come back to this in the discussion.

\subsection{Nonresponse and Costs}

Because only a small number of countries reported on costs, we could not include this variable in our analyses of response trends. However, as costs are an important topic in the survey literature (e.g., Groves 1989), we include a brief description of cost trend below.

Six countries (Belgium, Hungary, Norway, Portugal, Sweden and the United States) provided a trend report of raw costs per case in their own currency. This was corrected for inflation over the years and subsequently indexed as follows: the value reported for the first year (1998) was set at 100 for each country, thereby resolving differences in currencies. The dependent cost variable thus represents indexed cost per case, corrected for inflation. All countries reporting on costs report on the Labour Force Survey.

A multilevel analysis showed that this costs variable has no significant variance over surveys or countries $(p>.10)$, therefore a single level analysis suffices. This analysis shows that cost per case does increase over the years $(r=0.39, p=.001)$. A follow-up 
correlational analysis showed that for these six countries, the cost variable correlates negatively with noncontact $(r=-0.48, p<.001)$, but does not show a statistically significant correlation with refusal $(r=0.02, p=.89)$ or overall response $(r=-0.02$, $p=.89$ ). Thus, increasing cost is associated with lower noncontact rates only.

Costs can be seen as a proxy for effort, and the results above are in line with the conclusions of Beullens et al. (2018), who remark that in the European Social Survey many countries have increased their fieldwork efforts, and thus costs, in order to prevent response rates from falling. They report that increasing effort seem to have an effect on noncontact rates, but have been less effective in reducing refusal rates.

\section{Main Conclusions and Discussion}

In his review on adjustment techniques, Brick (2013) concluded that, although a lot of progress has been made in many areas of nonresponse research, the '. . . central problem, in our opinion, is that even after decades of research on nonresponse we remain woefully ignorant of the causes of nonresponse at a profound level'. In this study we tried to shed some light in the darkness by collecting, besides nonresponse data, also information on design and fieldwork variables.

We found that for a variety of surveys, response has been steadily declining internationally over the period 1998-2015. This is the result of an increase in both noncontacts and refusals over time (Research Question 1).

An interesting finding is that there are no differences in response trends between different surveys, so the downward trends are generalizable across different surveys (Research Question 2). Although the Labour Force Survey did have an overall higher response rate and lower refusal rate than the social surveys, the downward trends did not differ between the surveys. The higher response rate of the LFS is not surprising as it is a mandatory survey in many countries, while other social surveys are far less often mandatory.

While there are no differences in nonresponse trends between surveys in the period 1998-2015, there are differences in nonresponse trends between different countries (Research Question 3). This is in line with the recent findings for the European Social Survey by Beullens et al. (2018), for the Labour Force Survey (De Leeuw et al., 2018), and by Williams and Brick (2018) for the United States. In conclusion, there is ample empirical evidence that response rates continue to decline internationally, and that these trends differ between countries.

When focusing on these different trends between countries (Research Question 4), a more complicated picture emerges. The contextual variable differences in economic development of the individual countries are not related to response trends. Perhaps differences in economic development are less important than more subjective indicators, such as survey climate and individual attitudes towards surveys (Loosveldt and Joye 2016; De Leeuw et al. 2019). Unfortunately, this information was not available; in a future version of the nonresponse questionnaire, an assessment of survey climate could be added.

In general, refusal and response rates are better explained by the variables at our disposal than noncontact rates. A striking result is that none of the fieldwork effort variables is related to overall response, while most of the general design variables are related to response trends. A potential explanation may be the nature of the data structure. 
The data were collected at the survey level, and therefore do not contain information on individual contact attempts, about interviewer and respondent characteristics, and potential interactions. To obtain better insight in the latter, contact forms or process information over time are necessary. Unfortunately, this information is typically not available for most surveys and countries over a long period.

The majority of the design variables show relationships with response in the expected directions. For instance, mandatory surveys produce higher response rates than voluntary surveys. Allowing interventions in fieldwork procedures also leads to a higher response, a fact that may be related to the use of responsive or adaptive designs. Finally, using a mixed-mode design is related to a slightly lower response rate. This is understandable, since a single mode face-to-face survey is known to have the highest response rates (e.g., Bethlehem et al. 2011; Hox and De Leeuw 1994; Stoop 2005). In addition, much depends on the implementation of mixed-mode surveys, especially when online surveys are part of the mix (Dillman 2017; De Leeuw 2018).

However, several variables appear to have counterintuitive relationships. For example, the usage of R-indicators is related to lower response rates. It should be noted that decisions on survey design and fieldwork are often a reaction to declining response rates. In this case, when agencies experience decreasing response rates, the question is if this affects representativity, which can be checked with R-indicators. Another counterintuitive result is that none of the fieldwork effort variables is related to overall response. In the literature, there is ample evidence from experimental studies that show that providing incentives and converting refusals are effective in nonresponse reduction (AAPOR 2014; Singer 2002; Singer and Ye 2013). In our data, not all detail on fieldwork implementations at survey level was available or had a large amount of missing values. For instance, incentives-used was a binary variable. Information on type, amount, and implementation of incentive is lacking. Furthermore, inspection of the data showed that the lack of effect refusal conversion and incentives was not related to specific surveys, but was also found within surveys. This may indicate that agencies that encounter low or decreasing response rates increase their fieldwork efforts to counteract this effect (cf. Loosveldt 2019).

It should be emphasized that the reported relationships are descriptive (correlational). This means that a causal direction in many cases cannot be clearly established, and the absence of relations with fieldwork characteristics does not imply that fieldwork efforts are not important. This also means that survey practitioners cannot take these results directly in hand to inform on ways to improve their fieldwork designs. To determine causal directions, experimental designs need to be implemented in survey research (Lavrakas et al. 2019), and we recommend that agencies routinely use experimental designs to assess the effects of fieldwork changes.

Beside the descriptive nature of this study, a second limitation concerns the measurement quality. To obtain a long longitudinal time series on response trends, a retrospective questionnaire was sent to representatives of statistical institutes, and the retrospective nature may have influenced the data quality negatively. However, for a limited number of countries and years we were able to check our data. Eurostat has published LFS quality reports online for European countries since 2007. The correlations between equivalent variables in the two sources were extremely high (all correlations $>$.95), which gives us confidence in the quality of our data. Another measurement 
problem is the question whether countries use the same definition for noncontacts and refusals. Our instruction to the representatives who completed the questionnaires stressed that the same definition should be used throughout the reporting period. Nevertheless, different definitions between countries are possible. To the extent that countries did use different definitions, this would result in a higher country level error, and thus decrease the explained variance at the country level.

Finally, although we report evidence of increased expenditure over time, the cost data are limited to six countries and three surveys. Costs per case are increasing, and higher costs are related to lower noncontact rates, but not to fewer refusals or higher response rates. Cost data are in general difficult to obtain. To enhance nonresponse research in the future, we encourage that both data on cost and fieldwork efforts are included in survey methodological reports in more detail.

\section{Appendix : Explanatory Variables Used}

\begin{tabular}{|l|c|}
\hline Description & Available records \\
\hline Country context variable & 535 \\
\hline Class indicator socio-economic development & \\
\hline General design variables & 535 \\
\hline Survey is mandatory or not & 535 \\
\hline Person versus household/address sample & 535 \\
\hline Undersampling & 523 \\
\hline Oversampling & 535 \\
\hline Proxy allowed & 535 \\
\hline Substitution allowed for noncontact & 535 \\
\hline Substitution allowed for refusal & 535 \\
\hline More than one mode used & 535 \\
\hline Any representativity (R)indicator used & 535 \\
\hline Interventions in fieldwork & \\
\hline Effort in fieldwork variables & 504 \\
\hline Employment status (external interviewers versus own) & 517 \\
\hline Reward good performance interviewer & 517 \\
\hline Sanction poor performance interviewer & 517 \\
\hline Is refusal conversion used & 535 \\
\hline Reassignment to special interviewers & 535 \\
\hline Use of special letters to refusals & 535 \\
\hline Use of respondents incentives & 535 \\
\hline Control variables & \\
\hline Ineligibles controlled for in response rate & \\
\hline
\end{tabular}

Note: Variables were screened in a preliminary analysis on missingness and variance. Some variables could not be used in the final analysis, because of too many missing data or almost no variance. For example: the effort variables interviewer monitoring and use of advance letters are not used because of almost no variance (almost everybody does it); effort variables number of visits and calls could not be used because of too much missing information. All binary variables were recoded into $0=$ no, not applicable, $1=$ yes, applicable. 


\section{References}

AAPOR (American Association of Public Opinion Research) Task Force on Survey Refusals. 2014. Current Knowledge and Considerations Regarding Survey Refusals. Available at: http://www.aapor.org/AAPOR_Main/media/MainSiteFiles/RefusalTF_ FINAL090814.pdf (accessed 20 January 2020).

AAPOR: American Association of Public Opinion Research. 2016. Standard Definitions, Final Dispositions of Case Codes and Outcome Rates for Surveys. Available at: https://www.aapor.org/AAPOR_Main/media/publications/Standard-Definitions20169 theditionfinal.pdf (accessed 28 April 2020).

Atrostic, B.K., N. Bates, G. Burt, and A. Silberstein. 2001. "Nonresponse in US Government Household Surveys: Consistent Measures, Recent Trends, and New Insights.” Journal of Official Statistics 17: 209-226. Available at: https://www.scb.se/ contentassets/ca21 efb41fee47d293bbee5bf7be7fb3/nonresponse-in-u.s.-governmenthousehold-surveys-consistent-measures-recent-trends-and-new-insights.pdf (accessed 28 April 2020).

Bethlehem, J., F. Cobben, and B. Schouten. 2011. Handbook of Nonresponse in Household Surveys. New York: Wiley. DOI: https://doi.org/10.1002/9780470891056.

Beullens, K., G. Loosveldt, C. Vandenplas, and I. Stoop. 2018. "Response Rates in The European Social Survey: Increasing, Decreasing, or a Matter of Fieldwork Efforts?" Survey Methods: Insights from the Field. DOI: https://doi.org/10.13094/SMIF-201800003.

Biemer, P.P. and L.E. Lyberg. 2003. Introduction to Survey Quality. New York: Wiley. DOI: https://doi.org/10.1002/0471458740.

Bradburn, N. 1992. "A Response to the Nonresponse Problem: Presidential Address AAPOR.” Public Opinion Quarterly 56: 391-387. DOI: https://doi.org/10.1093/poq/ 56.3.391.

Brehm, J. 1993. The Phantom Respondents: Opinion Surveys and Political Representation. Ann Arbor: The University of Michigan Press. DOI: https://doi.org/10. 3998/mpub.9690285.

Brick, J.M. 2013. "Unit Nonresponse and Weighting Adjustments: A Critical Review." Journal of Official Statistics 29: 329-352. DOI: https://doi.org/10.2478/jos-2013-0026. Chun, A.Y., S.G. Heeringa, and B. Schouten. 2018. "Responsive and Adaptive Design for Survey Optimization.” Journal of Official Statistics 34: 581-597. DOI: https://doi.org/ 10.2478/jos-2018-0028.

Curtin, R., S. Presser, and E. Singer. 2005. "Changes in Telephone Survey Nonresponse Over the Past Quarter Century.” Public Opinion Quarterly 69: 87-98. DOI: https://doi. org/10.1093/poq/nfi002.

De Heer, W. 1999. "International Response Trends: Results of An International Survey." Journal of Official Statistics 15: 129-142. Available at: https://www.scb.se/contentassets/ca21efb41fee47d293bbee5bf7be7fb3/international-response-trends-results-ofan-international-survey.pdf (accessed 14 February 2020).

De Leeuw, E.D. 2018. "Mixed-Mode: Past, Present, and Future". Survey Research Methods, 17: 75-89. Available at: https://ojs.ub.uni-konstanz.de/srm/article/view/ 7402/6582 (accessed 20 January 2020). 
De Leeuw, E., and W. De Heer. 2002. “Trends in Household Survey Nonresponse: A Longitudinal and International Comparison." In Survey Nonresponse, Edited by R.M. Groves, D.A. Dillman, J.L. Eltinge, R.J.A. Little, 41-54. New York: Wiley.

De Leeuw, E., J. Hox, and A. Luiten. 2018. "International Nonresponse Trends Across Countries and Years: An Analysis of 36 Years of Labor Force Survey Data." Survey Methods: Insights from the Field. Available at: https://surveyinsights.org/?p = 10452 (accessed 28 April 2020).

De Leeuw, E., J. Hox, H. Silber, B. Struminskaya, and C. Vis. 2019. "Development of An International Survey Attitude Scale: Measurement Equivalance, Reliability, and Predictive Validity." Measurement Instruments for the Social Sciences, 1:9. DOI: https://doi.org/10.1186/s42409-019-0012-x.

Dillman, D.A. 2017. "The Promise and Challenges of Pushing Respondents to the Web in Mixed-Mode Surveys." Survey Methodology. Statistics Canada, Catalogue No. 12-001-X, Vol. 43, No. 1. Available at: http://www.statcan.gc.ca/pub/12-001-X/ 2017001/article/14836-eng.htm (accessed 5 May 2020).

Dillman, D.A. 1978. Mail and Telephone Surveys; the Total Design Method. New York: Wiley.

Dillman, D.A., J. L. Eltinge, R.M. Groves, and R.J.A. Little. 2002. “Survey nonresponse in design, data collection, and analysis". In Survey Nonresponse, Edited by R.M. Groves, D.A. Dillman, J.L. Eltinge, and R.J.A. Little: 3-26. New York: Wiley.

Dillman, D.A., J.D. Smyth, and L.M. Christian. 2014. Internet, Phone, Mail, and MixedMode Surveys. The Tailored Design Method, Fourth Edition. New York: Wiley.

Dutwin D. and P.J. Lavrakas. 2017. Trends in Telephone Outcomes, Appendix D to the Future of US General Population Telephone Survey Research AAPOR Task Force Report 2017. Available at: https://www.aapor.org/Education-Resources/Reports/TheFuture-Of-U-S-General-Population-Telephone-Sur.aspx?utm_source=link_newsv9\&utm_campaign_item_225143\&utm_medium=copy (accessed 14 February 2020).

Groves, R. 1989. Survey Errors and Survey Costs. New York: Wiley. DOI: https://doi.org/ $10.1002 / 0471725277$.

Groves, R.M. and M.P. Couper. 1998. Nonresponse in Household Survey Interviews. New York: Wiley. DOI: https://doi.org/10.1002/9781118490082.

Groves, R.M., F.J. Fowler, M.P. Couper, J.M. Lepkowski, E. Singer, and R. Tourangeau. 2004. Survey Methodology, Second Edition. New York: Wiley.

Guilford, J.P. and B. Fruchter. 1978. Fundamental Statistics in Psychology and Education. New York, London: McGraw-Hill.

Harris-Kojetin, B.A. and C. Tucker. 1999. "Exploring the Relations of Economic and Political Conditions With Refusal Rates to a Government Survey." Journal of Official Statistics 15: 167-184. Available at: https://www.scb.se/contentassets/ca21efb41fee $47 \mathrm{~d} 293$ bbee $5 \mathrm{bf} 7 \mathrm{be} 7 \mathrm{fb} 3 /$ exploring-the-relation-of-economic-and-political-conditions-with-refusal-rates-to-a-government-survey.pdf (accessed 14 April 2020).

Hox, J.J. and E.D. De Leeuw. 1994. “A Comparison of Nonresponse in Mail, Telephone, and Face-to-face Surveys; Applying Multilevel Models to Meta-Analysis." Quality and Quantity 28: 329-344. DOI: https://doi.org/10.1007/BF01097014. 
Hox, J., M. Moerbeek, and R. Van De Schoot. 2018. Multilevel Analysis. Techniques and Applications. New York, London: Routledge. DOI: https://doi.org/10.4324/ 9781315650982.

Larsen, L.J, J. Fane Lineback, and B.M. Reist 2020 "Continuing to Explore the Relation between Economic and Political Factors and Government Survey Refusal Rates: 1960-2015". Journal of Official Statistics, this issue.

Lavrakas, P.J., M.W. Traugott, C. Kennedy, A.L. Holbrook, E.D. De Leeuw, and B.T. West. 2019. Experimental Methods in Survey Research. Techniques That Combine Random Sampling With Random Assignment. New York: Wiley. DOI: https://doi.org/ 10.1002/9781119083771.

Loosveldt, G. 2019. Valedictory Address. Leuven: KU Leuven, November 15, 2019. Available at: https://soc.kuleuven.be/fsw/nieuws/emeritaat-geert-loosveldt (accessed June 2020).

Loosveldt, G. and D. Joye. 2016. "Defining and Assessing Survey Climate." In The Sage Handbook of Survey Methodology, Edited by C. Wolf, D. Joye, T.W. Smith, and Y-C Fu, 67-76. Los Angeles: Sage. DOI: https://doi.org/10.4135/9781473957893.n27.

Luiten, A., E. de Leeuw, B. Schouten, and J. Hox. 2016. "First Results of the (new) International Questionnaire on Nonresponse: Response of the LFS.” Paper Presented at International Workshop of Household Survey Nonresponse, Oslo, Norway, 31-8/1-9, 2016. Available at: https://www.nonresponse.org/uploadi/editor/DnD14871471489853 9LuiteneaInternationalQuestionnaire.docx (accessed June 2020).

Marken, S. 2018. Still Listening: The State of Telephone Surveys. Gallup. Available at: https://news.gallup.com/opinion/methodology/225143/listening-state-telephone-surveys.aspx (accessed 14 July 2019).

Muthén, L.K. and B.O. Muthén. 2017. Mplus User's Guide. Eight Edition. Los Angeles, CA: Muthén \& Muthén.

Pew Research. 2012. Assessing the Representativeness of Public Opinion Surveys. Available at: https://www.people-press.org/2012/05/15/assessing-the-representativeness-of-public-opinion-surveys/ (accessed 28 April 2020).

Schouten, B., N. Shlomo, and C. Skinner. 2011. "Indicators for Monitoring and Improving Representativeness of Response." Journal of Official Statistics. Available at: https://www.scb.se/contentassets/ca21 efb41fee47d293bbee5bf7be7fb3/indicators-formonitoring-and-improving-representativeness-of-response.pdf (accessed 28 April 2020).

Singer, E. 2002. "The Use of Incentives to Reduce Nonresponse in Household Surveys." In Survey Nonresponse, Edited by R.M. Groves, D.A. Dillman, J.L. Eltinge, and R.J.A. Little, 163-178. New York: Wiley.

Singer, E. and C. Ye. 2013. "The Use and Effects of Incentives in Surveys". The Annals of the American Academy of Political and Social Science 645: 112-141. DOI: https://doi.org/10.1177/0002716212458082.

Steeh, C. 1981. “Trends in Nonresponse Rates, 1952-1979.” Public Opinion Quarterly 45: 40-57. DOI: https://doi.org/10.1086/268633.

Stoop, I. 2005. The Hunt for the Last Respondent. The Hague: Social and Cultural Planning Office. Available at: https://www.scp.nl/english/Publications/Publications_- 
by_year/Publications_2005/The_Hunt_for_the_Last_Respondent (accessed 14 February 2020).

Stoop, I. 2016. "Unit Nonresponse“. In The Sage Handbook of Survey Methodology, Edited by C. Wolf, D. Joye, T.W. Smith, and Y-C Fu, 409-424. Los Angeles: Sage. DOI: https://doi.org/10.4135/9781473957893.n27.

Stoop, I., J. Billiet, A. Koch, and R. Fitzgerald. 2010. Improving Survey Response: Lessons Learned from the European Social Survey. Chichester: Wiley. DOI: https://doi.org/10. 1002/9780470688335.

Tabachnick, B.G., and L. Fidell. 2013. Using Multivariate Statistics. Boston, MA: Pearson.

Tourangeau, R., J.M. Brick, S. Lohr, and J. Li. 2016. “Adaptive and Responsive Survey Designs: A Review and Assessment." Journal of the Royal Statistical Society, Series A. 180: 203 223. DOI: https://doi.org/10.1111/rssa.12186.

Vehovar, V. 1999. "Field Substitution and Unit Nonresponse". Journal of Official Statistics, 15: 333-550. Available at: https://www.scb.se/contentassets/ca21efb41fee47d293bbee5bf7be7fb3/field-substitution-and-unit-nonresponse.pdf (accessed 28 April 2020).

Williams, D. and J.M. Brick. 2018. "Trends in US Face-to-Face Household Survey Nonresponse and Level of Effort”. Journal of Survey Statistics and Methodology 6: 186-211. DOI: https://doi.org/10.1093/jssam/smx019.

Received August 2019

Revised February 2020

Accepted May 2020 